\title{
Family psychosocial characteristics influencing criminal behaviour and mortality - possible mediating factors: a longitudinal study of male and female subjects in the Stockholm Birth Cohort
}

Britt af Klinteberg ${ }^{1,2,3^{*}}$, Ylva Almquist', Ulla Beijer ${ }^{3,4}$ and Per-Anders Rydelius ${ }^{3}$

\begin{abstract}
Background: Family psychosocial characteristics in childhood have been associated with children's development into criminal behaviour and mortality. This study explored these possible relationships and examined alcohol and/ or drug use and mental problems as possible mediating factors, highlighting gender-specific patterns.

Methods: Data from Swedish subjects born in $1953(n=14,294)$ from the Stockholm Birth Cohort study were examined. Several indicators of adverse family factors and individual problems were included in the present study. The information was derived from various data sources, covering different periods. Gender-specific associations with incidence of criminality (1966-1980) and mortality (1981-2009) were analysed using logistic regression. Furthermore, the population attributable fraction (PAF) was calculated for all variables in the fully adjusted models which were positively related to the outcome.

Results: Overall incidence of criminality and mortality was $(\mathrm{m} / \mathrm{f} 32.3 / 6.6)$ and $(\mathrm{m} / \mathrm{f} 6.1 / 3.5)$, respectively. The results showed that all aspects of family psychosocial and individual problems studied were associated with criminality for both genders. Among males, individual problems seemed to partly mediate these relations, but the associations remained statistically significant. Interestingly, the PAF analysis revealed a reduction in criminality of $17.5 \%$ when individual problems with alcohol and/or drug use were considered. Among females, a significant impact of alcohol and/or drug use on the association between family psychosocial characteristics and subsequent criminality was obtained. Inclusion of father's occupational class only somewhat reduced the estimates for the genders. Concerning male mortality, father's alcohol abuse was significantly related to an increased risk. When individual criminality was accounted for, the association was substantially reduced but remained statistically significant. Among females, when adjusting for family psychosocial factors, only the association between parents' mental problems and females' mortality was significant. None of the individual problem variables managed to explain this association.
\end{abstract}

Conclusions: Family psychosocial characteristics were associated with both subsequent criminal behaviour and mortality. These connections were partly explained by individual risk factors, especially by alcohol and/or drug use. The practical implications of the findings point to the importance of addressing the individual's alcohol and/or drug use in reducing criminal behaviour, which would also lower the mortality rates.

\footnotetext{
* Correspondence: bkg@psychology.su.se

${ }^{1}$ Centre for Health Equity Studies, Stockholm University/Karolinska Institutet,

Sveavägen 160, 5th floor, SE-106 91 Stockholm, Sweden

Full list of author information is available at the end of the article
} 


\section{Background}

Family psychosocial characteristics such as criminality, alcohol abuse, and mental problems are important to understand later criminal behaviour and premature death [1-5]. Most studies have, however, focused on male populations leaving it unclear whether these findings are also applicable to females. Moreover, there is a paucity of knowledge from longitudinal studies about individual factors that could possibly mediate these associations. The purpose of the present study is to examine gender differences in the influences of a variety of family psychosocial characteristics on the child's subsequent criminal behaviour and mortality and to see whether these influences could be mediated through different individual factors in the child.

Previous research has indicated that children from alcoholic families are at serious risk for developing various forms of problems as adults [6]. Already in an early follow-up study, the children of alcoholic fathers became criminals more often than other children [7]. A registerbased study of about 84,800 adolescents and young adults in Denmark, covering the age period of 15-27 years, reported that parental alcohol abuse may influence several long-term consequences, such as increased self-destructive behaviours including drug addiction, hospitalization due to violence, and mortality [8]. Another study demonstrated that maternal and paternal alcohol use behaviours were positively linked with children's alcohol use behaviours at 14 and 171/2 years of age, among both genders [2]. Furthermore, a longitudinal study of Swedish male conscripts reported that there is a clear association between fathers' consumption patterns and their own alcohol consumption as well as risk of early death [9].

Children of parents who abuse alcohol or other drugs are moreover found to have higher rates of emotional problems [10]. Even for young children parental alcohol abuse, especially among fathers, has shown to be associated with negative effects as evidenced in subsequent anxiety/depression symptoms influenced via greater levels of marital aggression [11]. A cross-sectional study on a large group of medical students confirmed that there is a strong relationship among parental alcoholism, adverse childhood experience, and subsequent personal alcohol abuse [12]. The results of a study on the impact of adverse childhood experiences on a wide variety of health behaviours and outcomes, showed that adults who grew up with both an alcohol-abusing mother and father had the highest likelihood of multiple forms of adverse childhood experiences, such as abuse, neglect, and other household dysfunctions as compared to those who had only one- or no alcohol-abusing parent [13].
Furthermore, in a 33-year longitudinal study of children of alcoholics, non-delinquent sons of alcoholic men (COA's) had more alcoholic relatives, more environmental stress, more emotional and medical problems, and poorer adjustments than their non-COA peers [14]. However, the COA's did not demonstrate poor results on intelligence tests, nor increased behaviour problems related to hyperactivity, otherwise found to be a strong predictor of both subsequent alcohol problems and violence [15]. However, even if genes have a very strong impact on the development of substance abuse, there is an important interaction between genes and environmental influences in this process $[16,17]$, as recently differently evidenced in male and female subjects [18]. In a study of individuals with substance use disorders and their adult first-degree relatives, there was an eight-fold increased risk of illicit drug disorders among the relatives as compared to their control group counterparts [19].

Generally, males are more likely to be at higher risk for early developed alcoholism, assumed to be more connected to biological and genetic factors, and distinguished from later developed alcoholism [20,21]. Early developed alcoholism is more frequently associated with additional problems like drug abuse and criminal behaviour than later developed alcoholism [22,21]. There are some indications of the existence of an early developed alcoholism related group also among female subjects [23]. A possible explanation for differences in reported results/indications between males and females could be that the hereditary form of alcoholism phenotypically expresses itself differently in females, despite the fact that the underlying genetic vulnerability might be the same.

It has furthermore been reported that individuals with addiction disorders have a higher occurrence of psychiatric and personality disorders [24]. This risk is nevertheless not equally distributed between the genders. While antisocial personality disorder dominates as the comorbid psychiatric diagnosis among alcohol dependent men, anxiety and depression are the most commonly reported diagnoses for women $[25,26]$. Studies have also shown a higher degree of alcoholism in families with a high degree of depression among women. To sum up, there seem to be differences concerning psychiatric comorbidity among alcohol-dependent- women and men.

An association between alcohol use or abuse and criminal behaviour, especially violent criminality, has also been reported in other groups [27-31]. In adolescents, higher alcohol consumption and more problematic alcohol and drug use was found in those with violence and conduct problems [32,33]. Strong connections between family history of alcohol abuse and 
violent offending were evidenced in a study by Linnoila and collaborators [34]. Notably, the vast majority of the offenders had committed crimes under the influence of alcohol.

Abused and neglected children, especially boys/males, had a higher likelihood of criminality, especially violence, compared with a control group with no experience of having been abused [35,36]. This is an important aspect in light of recent results reporting that many children have had an experience of living with parents having mental problems. A national survey in Canada that estimated the number of children exposed to parental psychiatric disorders, found that about 570,000 children under the age of 12 years were living with parents that had substance use, mood, or anxiety disorders [37]. Children with parents having mental problems have been found to have a higher risk to develop substance abuse and mental illness. Several studies have stated that children of parents with depression or substance misuse are at a higher risk of developing the same condition as the parent [38-42].

There is less research related to gender differences on the influences of family psychosocial characteristics [8]. However, boys with alcoholic parents tend to have an increased risk for criminal behaviour [6], and girls with maternal alcohol abuse and depression are found to have more serious mental problems than boys in the same situation [43]. Among outpatient adolescents and their parents, psychiatric problems among parents were found in $66 \%$ of the cases. The most common mental problem among fathers reporting alcohol abuse was depression (1/3). Fathers with both depression and alcohol problems were more frequent among the outpatient adolescent boys (29\%) than girls (5\%) [43].

Furthermore, a review of the effects of parental imprisonment on child antisocial behaviour and mental health showed that children of prisoners had about twice the risk of antisocial behaviour and poor mental health outcomes as compared to children whose parents were not imprisoned [3]. With regard to mortality, parental social class may have an influence on early death. In a prospective longitudinal study of men, where the fathers had a working-class occupation, 5\% had died by age 48, and early death was strongly linked with criminal behaviour already at age 8-10 years [1]. In a study of offspring of mothers with psychotic disorders, females had lower all-cause mortality and mortality from unnatural causes than male subjects [44].

There are relatively few studies on populations of atrisk children; the vast majority has focused on data from parents in treatment settings. One of the few studies that used population-based data, from the National Longitudinal Alcohol Epidemiological Survey, estimated that approximately one out of four American children under the age of 17 years were exposed to alcohol abuse or dependence in the family (lifetime) [45]. Thus, there is a need for using large longitudinal databases for researching the underlying links between family lifestyle/ characteristics and the development of criminal behaviour and mortality.

\section{Aim and hypothesis of the present study}

The overall aim of the present study was to examine the influences of family psychosocial characteristics on the child's subsequent criminal behaviour and mortality using longitudinal data from the Stockholm Birth Cohort study. Three explicit research questions were identified: first, how different family psychosocial characteristics in childhood, such as father's criminality and alcohol abuse, as well as parental mental problems, may influence children's development into criminal behaviour and mortality; second, whether these possible relationships could potentially be mediated by the individual's own alcohol and/or drug use and mental problems; and, third, whether there are differences in these possible patterns by gender.

\section{Methods \\ Subjects}

Data were obtained from the Stockholm Birth Cohort study (SBC), created in 2004-05 by a probability matching between two longitudinal data sets: the Stockholm Metropolitan Study (SMS) and The Swedish Work and Mortality Database (WMD). The SMS consists of all children born in 1953, who lived in the greater Stockholm area in 1963 ( $\mathrm{n}=15,117)$. It contains both survey data and routine registry data from 1953 through 1985. The WMD is an anonymous database that includes registry-based information on work, income, labour market position and various health outcomes. It includes all persons born before 31 December 1985, who were alive and resident in Sweden on 31 December 1980 and/or 31 December 1990. The SMS data were de-identified in 1986. Through a probability matching procedure, based on a matching algorithm that included 13 variables identical to both datasets (containing information about e.g. occupational and housing conditions of the parents, as well as month of birth and gender of the cohort member), 14,294 individuals were positively matched and thus included in the SBC [for a more detailed description, see 46]. Ethical permission was obtained from the Stockholm Regional Ethics Committee (No 739-03-629).

Several different indicators of family psychosocial characteristics and individual problems were included in the present study. Therefore additional data were taken from various sources, such as the Stockholm City Social Register, covering the years 1953-1972. This registry 
contains information on parents' alcohol abuse and mental health problems, divided into three periods: 1953-1959, 1960-1965, and 1966-1972. In addition to this, it also contains information about the causes for decisions made by the Child Welfare Committee regarding the cohort members (e.g. alcohol and drug use and mental problems), registered on a yearly basis between 1962 and 1972. While this information reflects a rather high degree of severity of individual problems, it should be noted that the investigations conducted by the Committee could have various implications, ranging from ad acta (no measures taken) to social care. Since keeping a Social Register is mandatory in all Swedish municipalities, the coverage is good. However, there are some certain conditions that should be noted. Firstly, although all cohort members were born in 1953, some lived outside of the Metropolitan area before 1963 (approximately $18 \%$ of the original cohort). Moreover, a small proportion of families moved out of (and sometimes back into) the Metropolitan area after 1963. Any events during that time therefore were recorded in another municipality's register. While this hypothetically could cause an underestimation of the occurrence of familyrelated problems, sensitivity analysis did not demonstrate any significant differences in the main associations when excluding these individuals from the study population (data not presented). Secondly, all cases in the Social Register were filed under the head of household, but as soon as the cohort members reached the age of 16 they were considered their own head of household and thus had dossiers of their own (until they got married, whereby girls would have their cases filed under the name of their husband). Because the Social Register is only available up until 1972, this issue of marriage only involves a few cases. Thirdly, when a cohort member's family or the cohort member her-/himself had been registered in the Social Register for any reason, they may have had a higher probability of being registered for additional reasons [47]. Thus, this may cause a stronger correlation between the different types of information regarding problematic individual behaviour as well as adverse family psychosocial characteristics.

Another central data source used was the National Crime Register (PBR), containing data on convictions. Information on fathers' crimes is available for three time periods: pre-1953, 1953-1959, and 1959-1972 (first six months of 1972), and includes conditional sentences (probation), unconditional sentences (imprisonment), and exemption from punishment due to institutional psychiatric care or alcohol treatment. Yearly information on the cohort members' own crimes is available for the period between 1966 and 1984. Records for children under the age of 15 were, however, only filed by the police in extremely serious cases. Moreover, minor offences committed by individuals under the age of 18 were eliminated five years after registration, and serious offences 10 years later, if no further crimes were recorded. Crime data were divided into seven categories: violent crimes, stealing, fraud, vandalism, traffic crimes, narcotic crimes, and other crimes.

\section{Measures}

The different variables concerning family psychosocial characteristics and individual problems are presented below. For the distribution of all variables according to gender, see Table 1.

\section{Family psychosocial characteristics}

Father's criminality A dichotomous variable, indicating if the father had committed any crime between 1953 and 1959 (child age 0-6), was created. Here, all types of sentence (i.e. conditional, unconditional, and exemption from punishment) were included.

Father's alcohol abuse Information on the father's alcohol abuse between 1953 and 1965 (child age 0-13) was included (regardless of whether or not the father was subject to institutional treatment or action by the temperance committee), categorised into 'yes' or 'no'.

Parents' mental health problems This information had already been categorised into 'psychiatric problems or depressed', 'receiving psychiatric treatment,' and 'committed suicide' (no additional information on the type of problem was thus available). Individuals whose father and/or mother were registered in any of these categories between 1953 and 1965 (child age 0-12) were considered as having a parent with mental health problems.

Father's occupational class This fourth type of information concerning family circumstances was included primarily as a control variable: father's occupational class in 1963 (child age 10). The categories were 'upper' (upper and upper middle class), 'middle' (officials and entrepreneurs), 'lower' (skilled and unskilled workers) and 'others' (unemployed, students and pensioners).

\section{Individual problems}

Criminality Two variables based on information about the individual's criminality were constructed. The first included all crimes that the cohort member committed between 1966 and 1980 (age 13-27), regardless of type. The second included only violent crimes (crimes against a person, e.g. physical violence and treats of physical violence such as assault, rape, robbery, molestation, and unlawful intrusion) during the same period.

Alcohol and/or drug use This information indicates whether or not actions were taken by the Child Welfare Committee due to the individual's use of alcohol and/or drugs any time during the period 1966-1972 (age 13-19). Mental problems Information on the individual's mental problems, covering the period 1966-1972 (age 13-19), refers to any actions taken by the Child Welfare 
Table 1 Distribution of family psychosocial characteristics, individuals problems and mortality according to gender (n $=14,294)$.

\begin{tabular}{|c|c|c|c|c|}
\hline & \multicolumn{2}{|c|}{ Males $(n=7,305)$} & \multicolumn{2}{|c|}{ Females $(n=6,989)$} \\
\hline & $\mathrm{n}$ & $\%$ & $\mathrm{n}$ & $\%$ \\
\hline \multicolumn{5}{|l|}{ Family psychosocial characteristics } \\
\hline \multicolumn{5}{|l|}{ Father's criminality (1953-1959) } \\
\hline No & 7,058 & 96.6 & 6,732 & 96.3 \\
\hline Yes & 247 & 3.4 & 257 & 3.7 \\
\hline \multicolumn{5}{|l|}{ Father's alcohol abuse (1953-1965) } \\
\hline No & 7,066 & 96.7 & 6,769 & 96.9 \\
\hline Yes & 239 & 3.3 & 220 & 3.1 \\
\hline \multicolumn{5}{|c|}{ Parents' mental problems (1953-1965) } \\
\hline No & 6.944 & 95.1 & 6.697 & 95.8 \\
\hline Yes & 361 & 4.9 & 292 & 4.2 \\
\hline \multicolumn{5}{|l|}{ Father's occupational class (1963) } \\
\hline Upper and upper middle class & 1,215 & 16.6 & 1,184 & 16.9 \\
\hline Middle class & 3,060 & 41.9 & 3,002 & 43.0 \\
\hline Working class & 2,810 & 38.5 & 2,644 & 37.8 \\
\hline Others & 220 & 3.0 & 159 & 2.3 \\
\hline \multicolumn{5}{|l|}{ Individual problems } \\
\hline \multicolumn{5}{|l|}{ Criminality - all crimes (1966-1980) } \\
\hline No & 4,943 & 67.7 & 6,530 & 93.4 \\
\hline Yes & 2,362 & 32.3 & 459 & 6.6 \\
\hline \multicolumn{5}{|c|}{ Criminality - violent crimes (1966-1980) } \\
\hline No & 6,775 & 92.7 & 6,921 & 99.0 \\
\hline Yes & 530 & 7.3 & 68 & 1.0 \\
\hline \multicolumn{5}{|c|}{ Criminality - non-violent crimes (1966-1980) } \\
\hline No & 5,014 & 68.6 & 6,548 & 93.7 \\
\hline Yes & 2,291 & 31.4 & 441 & 6.3 \\
\hline \multicolumn{5}{|c|}{ Alcohol and/or drug use (1966-1972) } \\
\hline No & 6,973 & 95.5 & 6,807 & 97.4 \\
\hline Yes & 332 & 4.5 & 182 & 2.6 \\
\hline \multicolumn{5}{|l|}{ Mental problems (1966-1972) } \\
\hline No & 7,149 & 97.9 & 6.897 & 98.7 \\
\hline Yes & 156 & 2.1 & 92 & 1.3 \\
\hline \multicolumn{5}{|l|}{ Mortality } \\
\hline \multicolumn{5}{|l|}{ Mortality (1981-2009) } \\
\hline No & 6,861 & 93.9 & 6,742 & 96.5 \\
\hline Yes & 444 & 6.1 & 247 & 3.5 \\
\hline
\end{tabular}

Committee due to such problems. No explicit information regarding the type or degree of severity is available, explaining why this category is very broad.

Mortality Information about mortality was available through the Cause of Death Register. Since the probability matching required that cohort members had to be alive at the end of 1980, the information covers the period 1981 through 2009 (age 28-56). All deaths, regardless of diagnosis, are included. Causes of death in these (young) ages are most likely linked to behavioural and lifestyle-related disturbances (e.g. alcohol and drug abuse), as well as external causes (e.g. suicide or accidents). Due to the rarity of mortality at these ages $(\mathrm{m} / \mathrm{f}$
6.1/3.5) it was not possible to examine specific causes of death.

\section{Statistical analysis}

The analyses were carried out using logistic regression, producing odds ratios. Since the association may be assumed to differ according to gender, all analyses were gender-specific. Table 2 (males) and Table 3 (females) show the association between adverse family psychosocial characteristics and criminality (all crimes). The first column demonstrates the 'crude' (i.e. unadjusted) association, whereas Model 1 takes into account all family psychosocial factors simultaneously. In Model 2, there is 
Table 2 Family psychosocial characteristics and criminality (all crimes) among males, adjusting for individual problems.

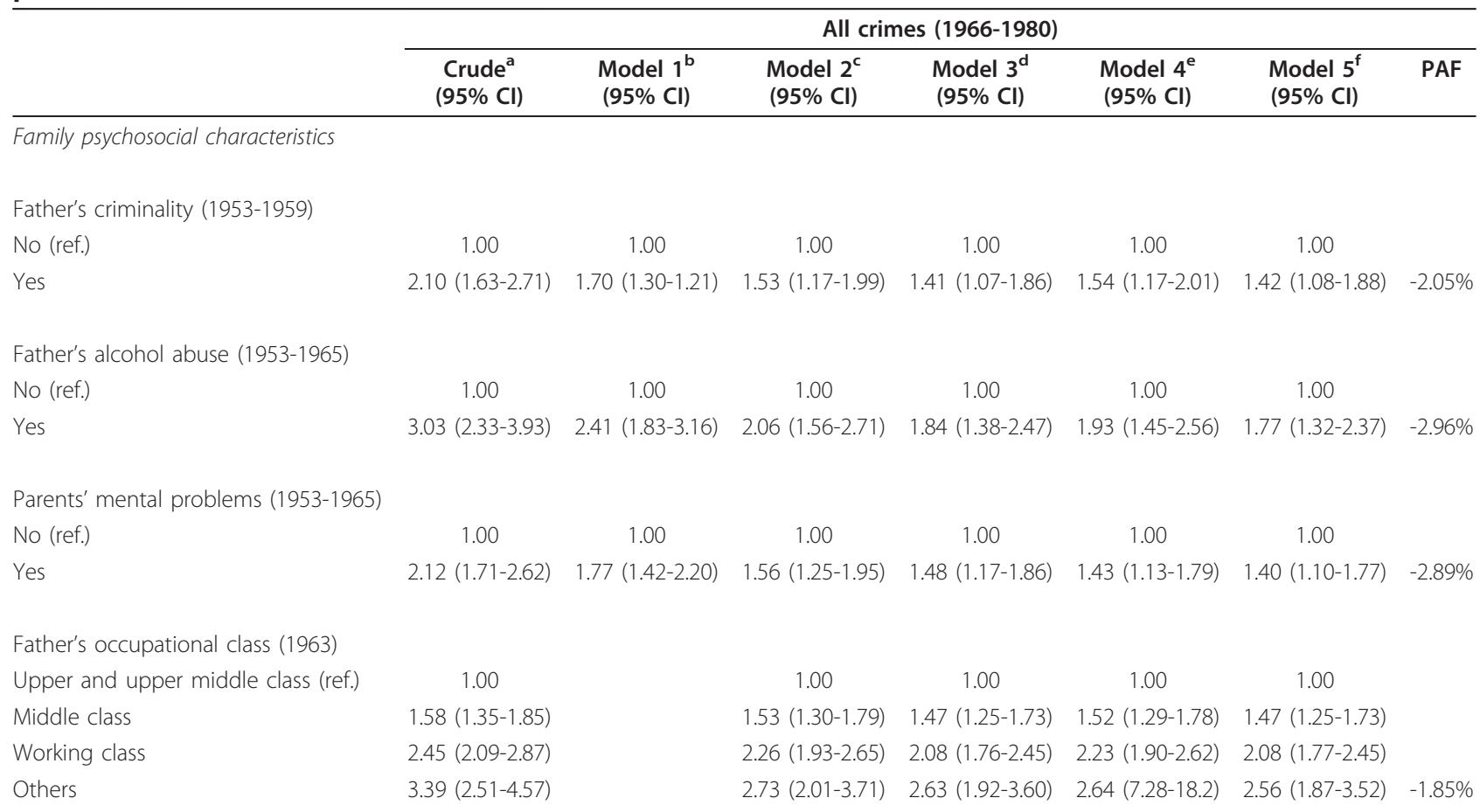

Individual problems

Alcohol and/or drug use (1966-1972)

No (ref.)

1.00

$22.3(15.5-32.3)$

1.00
$19.5(13.5-28.2)$

1.00

$15.2(10.5-22.2) \quad-17.5 \%$

Mental problems (1966-1972)

No (ref.)

1.00

$13.5(8.55-21.2)$ $\begin{array}{ccc}1.00 & 1.00 \\ 11.5(7.28-18.2) & 4.66(2.82-7.72) & -4.53 \%\end{array}$

Odds ratios from logistic regression analysis $(n=7,305)$.

${ }^{a}$ No adjustment, ${ }^{b}$ Mutual adjustment for family psychosocial characteristics, ${ }^{c}$ Mutual adjustment for family psychosocial characteristics + father's occupational class, ${ }^{d}$ Mutual adjustment for family psychosocial characteristics + father's occupational class + individual's alcohol and/or drug use, ${ }^{\mathrm{e}}$ Mutual adjustment for family psychosocial characteristics + father's occupational class + individual's mental problems, ${ }^{f}$ Mutual adjustment for all variables

additional adjustment for father's occupational class. Model 3 takes into account the individual's own alcohol and drug use, and Model 4 incorporates the effect of the individual's own mental problems. In Model 5, all variables are adjusted for simultaneously. Table 4 (males) and Table 5 (females) demonstrate the associations between adverse family psychosocial characteristics and mortality, taking individual problems into account. The first column presents the crude association between all family psychosocial characteristics and individual factors, in relation to mortality. In Model 1, the three indicators of adverse family psychosocial characteristics are included simultaneously, whereas in Model 2 father's occupational class is also included. Models 3-6 additionally adjust for one individual factor at a time. In the subsequent columns, Model 7 and Model 8, all factors are included (note: all crimes and violent crimes are separated due to overlap).

In addition, the population attributable fraction (PAF) was calculated for all terms in the fully adjusted models which were positively related to the outcome. Population attributable fraction refers to the proportion of the studied outcome that may be ascribed a given exposure (if the exposure would be causal). The PAF:s were derived by using the aflogit command in Stata 11.0, which is designed for logistic regression models [48]. The percentages are added to the final column of Table 2, 3, 4 and 5 (note: the PAF for 'all crimes' is based on Model 7 and the PAF for 'violent crimes' is based on Model 8, while the remaining PAF:s are based on a 
Table 3 Family psychosocial characteristics and criminality (all crimes) among females, adjusting for individual problems.

\begin{tabular}{|c|c|c|c|c|c|c|c|}
\hline & \multicolumn{7}{|c|}{ All crimes (1966-1980) } \\
\hline & $\begin{array}{l}\text { Crude }^{a} \\
(95 \% \text { Cl) }\end{array}$ & $\begin{array}{l}\text { Model 1 }{ }^{\mathrm{b}} \\
(95 \% \mathrm{Cl})\end{array}$ & $\begin{array}{l}\text { Model } 2^{c} \\
(95 \% \mathrm{CI})\end{array}$ & $\begin{array}{l}\text { Model } 3^{d} \\
(95 \% \mathrm{CI})\end{array}$ & $\begin{array}{l}\text { Model } 4^{\mathrm{e}} \\
(95 \% \mathrm{CI})\end{array}$ & $\begin{array}{l}\text { Model } 5^{f} \\
(95 \% \mathrm{Cl})\end{array}$ & PAF \\
\hline \multicolumn{8}{|c|}{ Adverse family psychosocial characteristics } \\
\hline \multicolumn{8}{|l|}{ Father's criminality (1953-1959) } \\
\hline No (ref.) & 1.00 & 1.00 & 1.00 & 1.00 & 1.00 & 1.00 & \\
\hline Yes & $2.52(1.75-3.61)$ & $1.83(1.25-2.69)$ & $1.71(1.17-2.52)$ & $1.31(0.83-2.05)$ & $1.68(1.12-2.50)$ & $1.32(0.84-2.07)$ & $-0.42 \%$ \\
\hline \multicolumn{8}{|l|}{ Father's alcohol abuse (1953-1965) } \\
\hline No (ref.) & 1.00 & 1.00 & 1.00 & 1.00 & 1.00 & 1.00 & \\
\hline Yes & $3.59(2.53-5.10)$ & $2.69(1.84-3.93)$ & $2.51(1.72-3.67)$ & $2.08(1.34-3.21)$ & $2.39(1.61-3.54)$ & $2.06(1.32-3.20)$ & $-0.83 \%$ \\
\hline \multicolumn{8}{|l|}{ Parents' mental problems (1953-1965) } \\
\hline No (ref.) & 1.00 & 1.00 & 1.00 & 1.00 & 1.00 & 1.00 & \\
\hline Yes & $2.45(1.74-3.46)$ & $1.84(1.28-2.65)$ & $1.70(1.18-2.46)$ & $1.43(0.94-2.17)$ & $1.49(1.01-2.19)$ & $1.40(0.92-2.13)$ & $-0.54 \%$ \\
\hline \multicolumn{8}{|l|}{ Father's occupational class (1963) } \\
\hline Upper and upper middle class (ref.) & 1.00 & & 1.00 & 1.00 & 1.00 & 1.00 & \\
\hline Middle class & $0.97(0.72-1.32)$ & & $0.92(0.68-1.25)$ & $0.79(0.57-1.08)$ & $0.90(0.66-1.22)$ & $0.80(0.58-1.10)$ & \\
\hline Working class & $1.69(1.27-2.26)$ & & $1.50(1.11-2.01)$ & $1.24(0.91-1.69)$ & $1.39(1.03-1.87)$ & $1.24(0.91-1.68)$ & \\
\hline Others & $2.31(1.33-4.02)$ & & $1.74(0.99-3.07)$ & $1.54(0.83-2.84)$ & $1.71(0.96-3.05)$ & $1.54(0.83-2.85)$ & $-0.33 \%$ \\
\hline
\end{tabular}

Individual problems

Alcohol and/or drug use (1966-1972)

No (ref.)

1.00

$33.1(24.0-45.7)$

1.00

$18.9(12.4-28.8)$
1.00

$29.2(21.0-40.6)$
1.00

$22.9(15.9-33.1) \quad-2.85 \%$

Mental problems (1966-1972)

No (ref.)

Odds ratios from logistic regression analysis $(n=6,989)$.

${ }^{a}$ No adjustment, ${ }^{b}$ Mutual adjustment for family psychosocial characteristics, ${ }^{c}$ Mutual adjustment for family psychosocial characteristics + father's occupational class, ${ }^{d}$ Mutual adjustment for family psychosocial characteristics + father's occupational class + individual's alcohol and/or drug use, ${ }^{e}$ Mutual adjustment for family psychosocial characteristics + father's occupational class + individual's mental problems, ${ }^{f}$ Mutual adjustment for all variables

model that includes both these variables). The PAF results given are non-overlapping.

\section{Results}

Associations between family psychosocial characteristics and criminality

As the first column in Table 2 demonstrates, all aspects of family psychosocial characteristics and individual problems are associated with criminality among males at a statistically significant level. For example, it is more than twice as common to be convicted for a crime among males whose father was a criminal (OR 2.10) or whose parents had mental problems (OR 2.12). Moreover, among those whose father abused alcohol, it is three times as common to subsequently be convicted. In the next column (Model 1), the three indicators of adverse family psychosocial characteristics have been included in the same model. The results show that they are independently associated with criminality among males. The inclusion of father's occupational class (Model 2) leads to some reduction of the estimates. In the next column (Model 3), the individual's alcohol and/ or drug use is added to the model. This causes an additional decrease of the estimates for the aspects of adverse family psychosocial characteristics, but the main findings remain intact. When information on the individual's mental problems is included instead (Model 4), the estimates are largely unchanged, indicating a paucity of mediating effects on the associations obtained. In the following column (Model 5), all variables are included 
Table 4 Adverse family psychosocial characteristics, individual problems, and mortality among males.

\section{Mortality (1981-2009)}

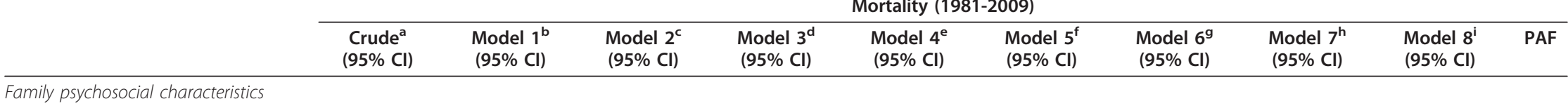

Father's criminality (1953-1959)

No (ref.)

1.00

1.00

1.00

1.00

1.00

1.00

1.00

Yes
Father's alcohol abuse (1953-1965)

No (ref.)

Yes

$1.46(0.92-2.30) \quad 1.10(0.68-1.78) \quad 1.05(0.65-1.69) \quad 0.97(0.60-1.57) \quad 0.97(0.59-1.57) \quad 0.90(0.55-1.48) \quad 1.03(0.64-1.68) \quad 0.88(0.54-1.44) \quad 0.89(0.54-1.46)$
1.00
1.00
1.00
1.00
1.00
1.00
1.00
1.00
1.00

Parents' mental problems (1953-1965)

No (ref.)

Yes

1.00

1.00

1.00

1.00

1.00

1.00

1.00

1.00

1.00

Father's occupational class (1963)

Upper and upper middle class (ref.)

Middle class

1.00

Working class

Others

Individual problems

All crimes (1966-1980)

No (ref.)

Yes

Violent crimes (1966-1980)

No (ref.)

Yes

Alcohol and/or drug use (1966-1972)

No (ref.)

Yes

Mental problems (1966-1972)

No (ref.)

(0.98-1.86)

$1.72(1.26-2.36)$

$2.93(1.77-4.83)$

1.00

$2.96(2.43-3.59)$

1.00

$3.71(2.89-4.77)$

1.00

$6.83(5.24-8.90)$

1.00

Yes $4.77(3.23-7.03)$

$\begin{array}{lrrrr}1.00 & 1.00 & 1.00 & 1.00 & 1.00\end{array}$

1.00

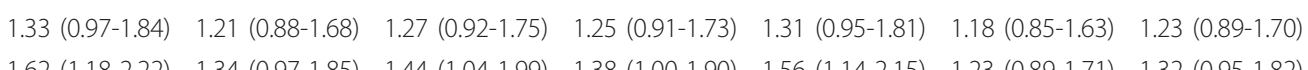
$1.62(1.18-2.22) \quad 1.34(0.97-1.85) \quad 1.44(1.04-1.99) \quad 1.38(1.00-1.90) \quad 1.56(1.14-2.15) \quad 1.23(0.89-1.71) \quad 1.32(0.95-1.82)$

$1.39(1.42-4.00) \quad 1.93(1.14-3.25) \quad 2.09(1.24-3.54) \quad 2.24(1.32-3.79) \quad 2.30(1.37-3.87) \quad 1.96(0.16-3.31) \quad 2.09(1.23-3.55) \quad-0.50 \%$

Odds ratios from logistic regression analysis $(n=7,305)$.
${ }^{a}$ No adjustment, ${ }^{b}$ Mutual adjustment for family psychosocial characteristics, ${ }^{c}$ Mutual adjustment for family psychosocial characteristics + father's occupational class, ${ }^{\mathrm{d}}$ Mutual adjustment for family psychosocial characteristics + father's occupational class + all crimes, ${ }^{\text {e }}$ Mutual adjustment for family psychosocial characteristics + father's occupational class + violent crimes

${ }^{\mathrm{f}}$ Mutual adjustment for family psychosocial characteristics + father's occupational class + alcohol and/or drug use, ${ }^{9}$ Mutual adjustment for family psychosocial characteristics + father's occupational class + mental

problems, ${ }^{\text {h }}$ Mutual adjustment for family psychosocial characteristics + father's occupational class + all crimes + alcohol and/or drug use + mental problems

'Mutual adjustment for family psychosocial characteristics + father's occupational class + violent crimes + alcohol and/or drug use + mental problems 
Table 5 Adverse family psychosocial characteristics, individual problems, and mortality among females.

$\frac{\text { Table } 5 \text { Adverse family psychosocial characteristics, individual problems, and mortality among females. }}{\text { Mortality }}$

\begin{tabular}{|c|c|c|c|c|c|c|c|c|c|c|}
\hline & \multicolumn{10}{|c|}{ Mortality (1981-2009) } \\
\hline & $\begin{array}{l}\text { Crude }^{a} \\
(95 \% \mathrm{Cl})\end{array}$ & $\begin{array}{l}\text { Model } 1^{\mathrm{b}} \\
(95 \% \mathrm{Cl})\end{array}$ & $\begin{array}{l}\text { Model } 2^{c} \\
(95 \% \mathrm{Cl})\end{array}$ & $\begin{array}{l}\text { Model } 3^{d} \\
(95 \% \mathrm{Cl})\end{array}$ & $\begin{array}{l}\text { Model } 4^{\mathrm{e}} \\
(95 \% \mathrm{Cl})\end{array}$ & $\begin{array}{l}\text { Model } 5^{f} \\
(95 \% \mathrm{Cl})\end{array}$ & $\begin{array}{l}\text { Model } 6^{9} \\
(95 \% \mathrm{Cl})\end{array}$ & $\begin{array}{l}\text { Model } 7^{\mathrm{h}} \\
(95 \% \mathrm{Cl})\end{array}$ & $\begin{array}{l}\text { Model 8i } \\
(95 \% \mathrm{Cl})\end{array}$ & PAF \\
\hline \multicolumn{11}{|c|}{ Family psychosocial characteristics } \\
\hline \multicolumn{11}{|c|}{ Father's criminality (1953-1959) } \\
\hline No (ref.) & 1.00 & 1.00 & 1.00 & 1.00 & 1.00 & 1.00 & 1.00 & 1.00 & 1.00 & \\
\hline Yes & $1.87(1.11-3.15)$ & $1.45(0.84-2.52)$ & $1.41(0.81-2.45)$ & $1.31(0.75-2.27)$ & $1.36(0.78-2.36)$ & $1.16(0.65-2.06)$ & $1.38(0.79-2.40)$ & $1.17(0.66-2.07)$ & $1.16(0.65-2.07)$ & $-0.16 \%$ \\
\hline \multicolumn{11}{|c|}{ Father's alcohol abuse (1953-1965) } \\
\hline No (ref.) & 1.00 & 1.00 & 1.00 & 1.00 & 1.00 & 1.00 & 1.00 & 1.00 & 1.00 & \\
\hline Yes & $2.22(1.31-3.75)$ & $1.57(0.89-2.77)$ & $1.53(0.87-2.69)$ & $1.26(0.71-2.24)$ & $1.50(0.84-2.65)$ & $1.26(0.70-2.26)$ & $1.46(0.83-2.57)$ & $1.14(0.63-2.06)$ & $1.27(0.71-2.29)$ & $-0.15 \%$ \\
\hline \multicolumn{11}{|c|}{ Parents' mental problems (1953-1965) } \\
\hline No (ref.) & 1.00 & 1.00 & 1.00 & 1.00 & 1.00 & 1.00 & 1.00 & 1.00 & 1.00 & \\
\hline Yes & $2.86(1.87-4.38)$ & $2.51(1.61-3.92)$ & $2.40(1.53-3.76)$ & $2.21(1.40-3.49)$ & $2.31(1.47-3.65)$ & $2.15(1.36-3.40)$ & $2.19(1.39-3.45)$ & $2.14(1.34-3.37)$ & $2.13(1.35-3.40)$ & $-0.93 \%$ \\
\hline
\end{tabular}

Upper and upper middle class (ref)

1.00

$0.86(0.59-1.25)$

$1.16(0.81-1.68)$

$1.87(0.92-3.81)$

Others

Individual problems

All crimes (1966-1980)

No (ref.)

Yes

Violent crimes (1966-1980)

No (ref.)

Yes

Alcohol and/or drug use (1966-1972)

No (ref.)

Yes

Mental problems (1966-1972)

No (ref.)

Yes

Odds ratios from logistic regression analysis $(n=6,989)$.

1.00

$4.15(3.01-5.73)$

1.00

$8.91(5.01-15.8)$

1.00

$8.02(5.45-11.8)$

1.00

$.08(4.16-12.1)$ $\begin{array}{ccccccc}1.00 & 1.00 & 1.00 & 1.00 & 1.00 & 1.00 & 1.00 \\ 0.82(0.56-1.20) & 0.83(0.57-1.21) & 0.82(0.56-1.20) & 0.78(0.53-1.13) & 0.82(0.56-1.19) & 0.79(0.54-1.15) & 0.77(0.53-1.13)\end{array}$

$1.05(0.72-1.52) \quad 0.99(0.68-1.45) \quad 1.03(0.71-1.50) \quad 0.94(0.65-1.38) \quad 0.99(0.68-1.44) \quad 0.92(0.63-1.35) \quad 0.94(0.64-1.37)$

$1.43(0.69-2.97) \quad 1.32(0.63-2.76) \quad 1.39(0.66-2.90) \quad 1.34(0.64-2.81) \quad 1.41(0.68-2.93) \quad 1.30(0.62-2.73) \quad 1.34(0.64-2.80) \quad-0.26 \%$

a No adjustment, ${ }^{\text {b }}$ Mutual adjustment for family psychosocial characteristics, ${ }^{c}$ Mutual adjustment for family psychosocial characteristics + father's occupational class, ${ }^{\text {d }}$ Mutual adjustment for family psychosocial characteristics + father's occupational class + all crimes, ${ }^{e}$ Mutual adjustment for family psychosocial characteristics + father's occupational class + violent crimes

${ }^{\mathrm{f}}$ Mutual adjustment for family psychosocial characteristics + father's occupational class + alcohol and/or drug use, ${ }^{9}$ Mutual adjustment for family psychosocial characteristics + father's occupational class + mental problems, ${ }^{\text {h}}$ Mutual adjustment for family psychosocial characteristics + father's occupational class + all crimes + alcohol and/or drug use + mental problems

'Mutual adjustment for family psychosocial characteristics + father's occupational class + violent crimes + alcohol and/or drug use + mental problems 
simultaneously. While the estimates are further reduced, all aspects of family psychosocial characteristics remain significantly associated with the individual's subsequent criminality.

In Table 3 the corresponding associations for females are demonstrated. Here as well, all aspects of family psychosocial characteristics and individuals problems are found to be associated with females' criminality. The second column (Model 1) includes the three indicators of adverse family psychosocial characteristics, which lead to a substantial decrease of the estimates. The estimates are further reduced when adjusted for father's occupational class (Model 2). In the fourth column (Model 3), the individual's alcohol and/or drug use is added to the model. This brings the association between father's criminality and females' own criminality, on the one hand, and parents' mental problems and females' own criminality, on the other hand, to a non-significant level. This reduction is not as great in the next column (Model 4) when there is an adjustment for individual mental problems. In the next column (Model 5), when all variables are included simultaneously, the decrease of the estimates primarily reflects the impact of females' own alcohol and/or drug use on the association between adverse family psychosocial characteristics and females' own subsequent criminality.

\section{Associations between family psychosocial characteristics and mortality}

Table 4 concerns the association between adverse family psychosocial characteristics and subsequent mortality among males. The first column demonstrates that of the three indicators of family psychosocial characteristics, only father's alcohol abuse is significantly related to mortality. It is three times as common (OR 3.00) among males with fathers who abused alcohol to die sometime between age 28 and age 56 as compared to other males. When all three indicators are adjusted for simultaneously (Model 1), the estimates decrease to some extent. They are further reduced when father's occupational class is added in the next column (Model 2). In the next column (Model 3), the individual's own criminality is accounted for: the association between father's alcohol abuse and mortality is substantially reduced but remains statistically significant. A slightly higher decrease is observed in the next column (Model 4), when only violent crimes are concerned. The following column (Model 5) adjusts for alcohol and/or drug use, which also leads to a decrease of the strength in the association. Where the individual's mental problems are considered, however, the estimate is not lowered as much (Model 6). In the next two columns, all variables are included simultaneously. However, the association between father's alcohol abuse and mortality still remains highly statistically significant.

The corresponding findings for females are shown in Table 5. As the first column demonstrates, all factors except father's occupational class are associated with subsequent mortality. The second column (Model 1) includes the three indicators of adverse family psychosocial characteristics simultaneously, this leaves the estimates for father's criminality and father's alcohol abuse at a statistically non-significant level. The association between parents' mental problems and females' mortality remains strong and statistically significant. In the next column (Model 2), father's occupational class is adjusted for, resulting in some reduction of the estimates. The following four columns adjust for different individual factors, separately: all crimes (Model 3), violent crimes (Model 4), alcohol and drug use (Model 5) and mental problems (Model 6). None of these explanatory variables manage to explain the association between parents' mental problems and females' subsequent mortality, although the estimate decreases to some extent. The next two columns include all variables. In both cases, it is still more than twice as common among females whose parents had mental problems to die between age 28 and age 56 .

\section{Population attributable fractions}

The results from the last column of Table 2 demonstrate the population attributable fractions for the different factors. For example, $2 \%$ of the cases of criminality among males could be avoided if the effect of father's alcohol abuse was eliminated. The corresponding PAF for the individual's alcohol and drug use is $17.5 \%$ (or 413 persons). The similar pattern is demonstrated for females (Table 3), although the point estimates for the PAF:s are much lower. Worth noticing is that in addition to the PAF:s being lower, the crime rate among females is also considerably lower, explaining why eliminating the exposure of certain factors would affect even fewer persons (e.g., 13 persons if the exposure to alcohol and drug use was removed).

In Table 4 the last column shows the population attributable fractions for mortality among males. The results demonstrate that only $0.7 \%$ of the mortality cases among men may be attributed to father's alcohol abuse. Of the factors related to individual problems, $8.5 \%$ of the cases in mortality (or 37 persons) are attributable to the individual's own criminality (all crimes) whereas the corresponding figure for alcohol and drug use is $2.0 \%$. Concerning females' mortality (Table 5 ), the population attributable fractions for family psychosocial characteristics factors are very small. The pattern shown for males' individual problems emerges in females as well. 
However, again, the estimates are considerably lower: approximately $1.6 \%$ and $0.9 \%$ of the deaths among females may be attributed to their criminality and alcohol and drug use, respectively.

\section{Discussion}

The aim of the present study was to investigate the association between family psychosocial characteristics and the individual's development into criminal behaviour and mortality. Three research questions were included: first, how different family psychosocial characteristics in childhood may influence children's development into criminal behaviour and mortality; second, potential mediation by the individual's own alcohol and/ or drug use and mental problems; and, third, possible differences in these patterns by gender.

\section{Influences on the outcome variable criminality}

The different indicators of family psychosocial characteristics (father's criminality, father's alcohol abuse and parents' mental problems) were strongly associated with subsequent criminality in the male group in line with earlier research $[8,49-51]$. These associations might, apart from familial/genetic influences, also be interpreted as due to social modelling, as well as shared risk factors such as peer factors and individual features $[52,53]$. Among females, however, having a father abusing alcohol appeared to be more important for their criminal behaviour than the father's criminality, or either of the parents having mental problems. Worth noticing, these associations were also similar when only violent crimes were considered as the outcome (data not presented). These associations were largely unexplained by the occupational class during childhood. Interestingly, this is in line with earlier results from a Swedish study reporting the same influence of alcoholic fathers, comparing those from the highest- and lowest social class, on their children's development of juvenile delinquency [54]. Furthermore, in the present study, both for males and females, statistically significant links between individual problems, in terms of alcohol and/or drug use as well as mental problems, and criminality were found. This is of special interest, since these individual problems in the present study covered the age period of 13-19 years, and thus indicate that early-onset alcohol problems were closely connected to criminal behaviour and a family history of alcohol abuse [22]. Additionally, to some extent, these individual problems seemed to possibly mediate the association between family psychosocial characteristics and the individual's own subsequent criminality. It is noteworthy, however, that females' own alcohol and/or drug abuse overrode the effect of adverse family characteristics on criminality.

\section{Influences on the outcome variable mortality}

The present results further suggested that deaths in the age range of 28 to 56 years are more common among males whose fathers abused alcohol as compared to their male counterparts. No corresponding associations seemed to apply for father's criminality or mental problems in the parents. The results can be compared with findings from another study [8] reporting parents' abuse of alcohol having consequences for their children (both males and females) during the age period of 15 to 27 years in terms of mortality and hospitalization due to violence. In the present study however, among females, parents' mental problems emerged as the most important of the family psychosocial characteristics investigated for the outcome of early death (this was the case regardless of whether these problems occurred in the mother or the father, data not presented). These are new findings and should be further studied. Childhood social class did not seem to confound this relationship to any large extent. With regard to individual problems, criminality (all crimes as well as violent crimes), alcohol and/or drug use, and, to a lesser extent, mental problems, contributed to parts of the explanation to the associations between family psychosocial characteristics and subsequent mortality. This was the case for both male and female subjects.

\section{Strengths and limitations}

The prospective design of the Stockholm Birth Cohort database permitted the study of development into criminal behaviour and mortality. Moreover, the richness of the data made it possible to include a variety of indicators of family psychosocial characteristics and individuals problems. The large-scale data material also enabled us to perform gender-specific analysis in order to examine whether the patterns of association studied differed for males and females. There are nevertheless some issues that need to be recognised. Firstly, although the longitudinal data allowed for temporal ordering of the variables, no inference about causality can be made. The pathways leading to criminal behaviour and, not the least, to mortality are multifaceted and involve a complex interplay between family psychosocial characteristics and individual problems in the developmental context. Secondly, given the explorative approach of the present study, the investigated indicators were defined in terms of relatively broad categories. Future studies should aim at investigating these aspects in more detail, as well as including other sets of explanatory factors such as intelligence, other school-related indicators, and personality factors. Thirdly, the outcomes were captured through a rather lengthy follow-up (14 years for criminality and 28 years for mortality). The types of criminality 
and cause of death were likely to vary by age, which could make it more complicated to disentangle the contributions of the family-related- and individual risk indicators studied to subsequent criminal behaviour and mortality. Finally, although attrition was very low in the analysis, the study sample contains some individuals whose families were not resident in the actual Stockholm area before 1963, and some individuals who could have moved (in and) out of the area after 1963. The prevalence of family-related characteristics and individual problems could thus have been underestimated, which is likely also to cause an underestimation of the magnitude of the relationships obtained.

\section{Practical implications of the findings}

The present study indicated that family psychosocial characteristics during childhood are associated with the child's subsequent criminal behaviour and mortality. To some extent, these influences appeared to operate through individual risk factors, such as alcohol and/or drug use and mental problems (for mortality also the risk factor of criminality). In order to give a more balanced picture, which reaches over and above the one that may be obtained by multivariate analysis, population attributable fractions were calculated. Results indicated that although the associations were strong, removing the exposure of father's alcohol abuse and criminality as well as parents' mental problems would not decrease the cases of criminality (a total decrease of $7.9 \%$ for males and $1.8 \%$ for females) or mortality (a total decrease of $1.2 \%$ for males as well as for females) to any large extent. Interestingly, however, having had no individual problems the incidence of criminality would have decreased greatly among males (a total decrease of 519 cases) or mortality (a total decrease of 53 cases), lesser so among the females (14 and 5 cases, respectively). Thus, the practical implications of the present study point to the importance of the individual's alcohol and/or drug use in reducing criminal behaviour, particularly among males. Moreover, any reduction in criminality would subsequently lower the mortality rates. This interpretation is however restricted to the framework of the current study. To eliminate the effect of adverse family psychosocial characteristics is still likely to be highly beneficial for other types of outcomes in the child, such as psychological well-being and school achievement, which in turn could have an impact on opportunities, achievements, and lifestyle in adulthood. Furthermore, there is still a substantial part of the development into criminal behaviour and subsequent mortality that remains unaccounted for by the risk factors included here. Thus, the findings of the present study should be considered in light of these arguments. It is also necessary to discuss whether our findings, as they are based on a Swedish cohort, are applicable to other settings. In comparison to many other countries, Sweden has a generous welfare system in part designed to compensate for unequal living conditions across social groups. This could possibly indicate that the safety net for individuals growing up in families with more adverse family psychosocial characteristics is more comprehensive compared to other cultural and societal settings.

\section{Conclusions}

The findings of the present study suggested that family psychosocial characteristics were associated with the child's subsequent criminal behaviour and mortality. These connections partly seemed to be mediated by individual risk factors, especially by alcohol and/or drug use, somewhat differently operating in the male and female groups. The practical implications of the findings point to the importance of the individual's alcohol and/ or drug use in reducing criminal behaviour, which according to the present findings would also lower the mortality rates.

\section{Acknowledgements}

The present research was made possible by access to data from a Swedish database, the Stockholm Birth Cohort. The creation and maintenance of the Stockholm Birth Cohort database represents a collaboration between CHESS and SOFI, financed by the Swedish Research Council. Sten-Åke Stenberg at SOFI prepared the original Metropolitan database, Denny Vågerö at CHESS prepared the follow-up data for 1980-2002, and Reidar Österman at CHESS organised the probability matching of the two data sets. The research was supported by grants from the Swedish Prison and Probation Service (Grant Dnr: 09-01-51, to BaK/PAR). Special thanks are forwarded to Lars Brännström for statistical assistance and to Professor Valerie DeMarinis for editing the manuscript.

\section{Author details}

${ }^{1}$ Centre for Health Equity Studies, Stockholm University/Karolinska Institutet, Sveavägen 160, 5th floor, SE-106 91 Stockholm, Sweden. ${ }^{2}$ Department of Psychology, Stockholm University, Stockholm, Sweden. ${ }^{3}$ Department of Women's and Children's Health, Karolinska Institutet, Stockholm, Sweden. ${ }^{4}$ Department of Public Health, Karolinska Institutet, Stockholm, Sweden.

\section{Authors' contributions}

BaK, the scientific leader of the project, conducted the preliminary design, participated in presenting the results, provided the supervision and the interpretation of data, drafting of the manuscript, and gave the final design and shape of the manuscript. YA was responsible for the statistical analysis, participated in the study design, presentation of the results and discussion, and drafting of the manuscript. UB participated in the study design, background, discussion, and drafting of the manuscript. P-AR conducted the preliminary design and contributed to the drafting of the manuscript. All authors have read and approved the final manuscript.

\section{Authors' information}

Britt af Klinteberg, PhD, Professor of Psychology, Stockholm University, and affiliated Professor with the Department of Women's and Children's Health, Karolinska Institutet, Stockholm; Ylva Almquist, PhD, post doctoral researcher at CHESS, Stockholm University/Karolinska Institutet, Stockholm; Ulla Beijer, $\mathrm{PhD}$, researcher at the Department of Women's and Children's Health, Karolinska Institutet, Stocholm; Per-Anders Rydelius, MD, PhD, Professor of Pediatrics, Department of Women's and Children's Health, Karolinska Institutet, Stockholm 


\section{Competing interests}

The authors declare that they have no competing interests.

Received: 2 December 2010 Accepted: 2 October 2011

Published: 2 October 2011

\section{References}

1. Shepherd JP, Shepherd I, Newcombe RG, Farrington D: Impact of antisocial lifestyle on health: chronic disability and death by middle age. Journal of Public Health 2009, 31:506-511.

2. Latendresse SJ, Rose RJ, Viken RJ, Pulkkinen L, Kaprio J, Dick DM: Parenting mechanisms in links between parents' and adolescents' alcohol use behaviors. Alcoholism Clinical and Experimental Research 2008, 32:322-330.

3. Murray J, Farrington DP, Sekol I, Olsen RF: Effects of parental imprisonment on child antisocial behaviour and mental health: a systematic review. Campbell Systematic Reviews 2009 2009, 4.

4. Rydelius P-A: Children of alcoholic fathers. Their social adjustment and their health status over 20 years. Acta Paediatrica Scandinavica 1981, , Supplement 286: 1-89.

5. Nordberg L, Rydelius P-A, Zetterström R: Children of alcoholic parents: health, growth, mental development and psychopathology undtil school age. Acta Paediatrica Scandinavica 1993, , Supplement 387: 1-24.

6. Rydelius P-A: Annotation: Are children of alcoholics a clinical concern for child and adolescent psychiatrists of today? The Journal of Child Psychology and Psychiatry 1997, 38:615-624.

7. Otterstrom E: Delinquency and children from bad homes (thesis). Acta Paediatrica Scandinavica 1946, 33(Suppl No 5).

8. Nygaard Christoffersen MN, Soothill K: The long-term consequences of parental alcohol abuse: a cohort study of children in Denmark. Journal of Substance Abuse Treatment 2003, 25:107-116.

9. Andréasson $\mathrm{S}$, Allebeck P, Romelsjö A: Alcohol and mortality among young men: longitudinal study of Swedish conscripts. BMJ 1988, 296:1021-1025.

10. Bygholm Christensen HB, Bilenberg $\mathrm{N}$ : Behavioural and emotional problems in children of alcoholic mothers and fathers. European Child \& Adolescent Psychiatry 2000, 9:219-226.

11. Eiden RD, Molnar DS, Colder C, Edwards EP, Leonard KE: A conceptual model predicting internalizing problems in middle childhood among children of alcoholic and nonalcoholic fathers: The role of marital aggression. Journal of Studies on Alcohol and Drugs 2009, 70:741-750.

12. Xiao Q, Dong $M-X$, Yao J, Li W-X, Ye D-Q: Parental alcoholism, adverse childhood experiences and later risk of personal alcohol abuse among Chinese medical students. Biomedical and environmental sciences 2008, 21:411-419.

13. Dube SR, Andaa RF, Felittib VJ, Crofta JB, Edwardsa VJ, Gilesa WH: Growing up with parental alcohol abuse: exposure to childhood abuse, neglect, and household dysfunction. Child Abuse \& Neglect 2001, 25:1627-1640.

14. Drake RE, Vaillant GE: Predicting alcoholism and personality disorder in a 33-year longitudinal study of children of alcoholics. British Journal of Addiction 1988, 83:799-807.

15. af Klinteberg B, Andersson T, Magnusson D, Stattin H: Hyperactive behavior in childhood as related to subsequent alcohol problems and violent offending: A longitudinal study of male subjects. Personality and Individual Differences 1993, 15:381-388.

16. Cloninger RC, Bohman M, Sigvardsson S: Inheritance of alcohol abuse. Archives of General Psychiatry 1981, 38:861-868.

17. Tuvblad C, Grann M, Lichtenstein P: Heritability for adolescent antisocial behavior differs with socioeconomic status: gene-environment interaction. The Journal of Child Psychology and Psychiatry 2006, 47(7):734-743

18. Nilsson KW, Comasco E, Åslund C, Nordquist N, Leppert J, Oreland L: MAOA genotype, family relations and sexual abuse in relation to adolescent alcohol consumption. Addiction Biology 2010.

19. Merikangas KR, Stolar M, Stevens DE, Goulet J, Preisig MA, Fenton B, Zhang H, O'Malley SS, Rounsaville BJ: Familial transmission of substance use disorders. Archives or General Psychiatry 1998, 55:973-979.

20. von Knorring $L$, Oreland $L$ : Platelet MAO activity in type 1 /type 2 alcoholics. Alcoholics: Clinical and Experimental Research 1996, 20(8):224a-230a.
21. von Knorring L, von Knorring A-L, Smigan L, Lindberg U, Edholm M: Personality traits in subtypes of alcoholics. Journal of Studies on Alcohol 1987, 48(6):523-527.

22. Cloninger CR, Sigvardsson S, Bohman M: Type I and type II alcoholism: An update. Alcohol Health \& Research World 1996, 20:18-23.

23. Hallman J, Persson M, af Klinteberg B: Female alcoholism: differences between female alcoholics with and without a history of additional substance abuse. Alcohol and Alcoholism 2001, 36(6):564-571.

24. Beijer U, Andréasson S: Gender, hospitalization and mental disorders among homeless people compared with the general population in Stockholm. European Journal of Public Health 2010, 20(5):511-516.

25. Fridell $M$, Hesse $M$, Johnsson E: High prognostic specificity of anti-social personality disorder in patients with drug dependence: results from a five-year follow-up. The American Journal on Addictions 2006, 15:227-232.

26. Greenfield SF, Brooks AJ, Gordon SM, Green CA, Kropp F, McHugh RK, Lincoln M, Hien D, Miele GM: Substance abuse treatment entry, retention, and outcome in women: a review of the literature. Drug and Alcohol Dependence 2007, 86:1-21.

27. Caspi A, Begg D, Dickson N, Harrington H-L, Langley J, Moffitt TE, Silva PA: Personality differences predict health-risk behaviors in young adulthood: Evidence from a longitudinal study. Journal of Personality and Social Psychology 1997, 73(5):1052-1063.

28. Nash Parker R, Auerhanh K: Alcohol, drugs and violence. Annual Review of Sociology 1998, 24:291-311.

29. Richardson A, Budd T: Young adults, alcohol, crime and disorder. Crim Behav Ment Health 2003, 13(1):5-16.

30. White HR, Loeber R, Stouthamer-Loeber M, Farrington DP: Developmental associations between substance use and violence. Development and Psychopathology 1999, 11(4):785-803.

31. Virkkunen M, Goldman D, Nielsen DA, Linnoila M: Low brain serotonin turneover rate (low CSF 5-HIAA) and impulsive violence. Journal of Psychiatry and Neuroscience 1995, 20(4):271-275.

32. Farrington DP, Loeber R: Epidemiology of juvenile violence. Child and Adolescent Psychiatric Clinics of North America 2000, 9(4):733-748.

33. White HR, Xie M, Thompson W, Loeber R, Stouthamer-Loeber M: Psychopathology as a predictor of adolescent drug use trajectories. Psychology of Addictive Behaviours 2001, 15(3):210-218.

34. Linnoila M, De Jong J, Virkkunen M: Family history of alcoholism in violent offenders and impulsive fire setters. Archives of General Psychiatry 1989, 46:613-616.

35. Widom CS: The cycle of violence. Science 1989, 244:160-166.

36. Lang S, af Klinteberg B, Alm P-O: Adult psychopathy and violent behavior in men with early neglect and abuse. Acta Psychiatrica Scandinavica 2002, 106(Suppl 412):93-100.

37. Bassani DG, Padoin CV, Philipp D, Velduizen S: Estimation the number of children exposed to parental psychiatric disorders through a national health survey. Child and Adolescent Psychiatry and Mental Health 2009, 3:1-7.

38. Beardslee W, Bemporad J, Keller M, Klerman G: Children of parents with major affective disorder: a review. American Journal of Psychiatry 1983, 140:825-835.

39. Beardslee $W$, Versage $E_{1}$ Gladston T: Children of affectively ill parents: a review of the past 10 years. Journal of the American Academy of Child \& Adolescent Psychiatry 1998, 37:1124-1141.

40. Essex MJ, Kraemer HC, Armstrong JM, Boyce WT, Goldsmith HH, Klein MH, Woodward $\mathrm{H}$, Kupfer DJ: Exploring risk factors for the emergence of children's mental health problems. Archives of General Psychiatry 2006, 63:1246-1256.

41. Schubert EW, McNeil TF: Prospective study of adult mental disturbance in offspring of women with psychosis. Archives of General Psychiatry 2003, 60:473-480.

42. Cuijpers P, Steunenberg B, van Straten A: When children of problem drinkers grow old: does the increased risk of mental disorders persist? Addictive Behaviors 2006, 31:2284-2291.

43. Peiponen S, Laukkanen E, Korhonen V, Hintikka U, Lehtonen J: The association of parental alcohol abuse and depression with severe emotional and behavioural problems in adolescents: a clinical study. International Journal of Social Psychiatry 2006, 52:(395-407).

44. Suvisaari J, Häkkinen L, Haukka J, Lönnqvist J: Mortality in offspring of mothers with psychotic disorder. Psychological Medicine 2008, 38:1203-1210. 
45. Grant B: Estimates of US children exposed to alcohol abuse and dependence in the family. American Journal of Public Health 2000, 90:112-115.

46. Stenberg $S-\AA ̊ A$, Vågerö D, Österman R, Arvidsson E, von Otter C, Janson C-G: Stockholm Birth Cohort Study 1953-2003: A new tool for life-course studies. Scandinavian Journal of Public Health 2006, 35(1):104-110.

47. Janson C-G: Register Data I. A code book. Research Report No 12 Stockholm: Swedish Institute for Social Research; 1980.

48. Greenland S, Drescher K: Maximum likelihood estimation of the attributable fraction from logistic models. Biometrics 1993, 49:865-872.

49. Bohman M, Sigvardsson S, Cloninger R, von Knorring AL: Alcoholism: lessons from population, family and adoption studies. Alcohol Alcohol Suppl 1987, 1:55-60.

50. Farrington DP, Jolliff $D$, Loeber R, Stouthamer-Loeber M, Kalb L: The concentration of offenders in families, and family criminality in the prediction of boys' delinquency. Journal of Adolescence 2001, 24:579-596.

51. Farrow JA, French J: The drug abuse-delinquency connection revisited. Adolescence 1986, 21(84):951-960.

52. Fergusson DM, Lynskey MT, Horwood L: Alcohol misuse and juvenile offending in adolescence. Addication 1996, 91:483-494.

53. Milgram GG: Adolescents, alcohol and aggression. Journal of Studies on Alcohol 1993, Supplement No 11: 53-61.

54. Nylander I, Rydelius P-A: A comparison between children of alcoholic fathers from excellent versus poor social conditions. Acta Paediatrica Scandinavica 1982, 71:809-813.

\section{Pre-publication history}

The pre-publication history for this paper can be accessed here: http://www.biomedcentral.com/1471-2458/11/756/prepub

doi:10.1186/1471-2458-11-756

Cite this article as: Klinteberg et al: Family psychosocial characteristics influencing criminal behaviour and mortality - possible mediating factors: a longitudinal study of male and female subjects in the Stockholm Birth Cohort. BMC Public Health 2011 11:756.

\section{Submit your next manuscript to BioMed Central} and take full advantage of:

- Convenient online submission

- Thorough peer review

- No space constraints or color figure charges

- Immediate publication on acceptance

- Inclusion in PubMed, CAS, Scopus and Google Scholar

- Research which is freely available for redistribution

Submit your manuscript at www.biomedcentral.com/submit
CioMed Central 